\title{
Ball game watching theory in the teaching site
}

\section{Shugang Liu, Xiufang Li, Chin-Jung Chuang}

Shugang Liu, Xiufang Li, Chin-Jung Chuang, "Ball game watching theory in the teaching site," Proc. SPIE 10452, 14th Conference on Education and Training in Optics and Photonics: ETOP 2017, 104521N (16 August 2017); doi: $10.1117 / 12.2269383$

SDIE Event: 14th Conference on Education and Training in Optics and Photonics, ETOP 2017, 2017, Hangzhou, China 


\title{
Ball Game Watching Theory in the Teaching Site
}

\author{
Liu Shugang*a, Li Xiufang ${ }^{\mathrm{b}}$, Chin-Jung Chuang ${ }^{\mathrm{c}}$, \\ ${ }^{a}$ Dept of EEE, Heilongjing University, Harbin 150080, PR China \\ ${ }^{b}$ Daheng New Epoch Technology Inc, Beijing 10085, PR China \\ ${ }^{c}$ Department of Opto-electronic Engineering, National Dong Hwa University, 97401 Taiwan
}

\begin{abstract}
Lecturing is a common approach in the traditional teaching site. In this paper, we bring a modern model "ball game watching theory" to explain the situation in the classroom. The reason why the audiences going to the court is to enjoy the atmosphere, and it is also the reason why student joining to the class. A successful class running is to create studious atmosphere. However, once the teacher does the demo in the class, the multimedia tool must be used to show the details, as the big display working in the court. The key moment is recorded and the details are magnified. when teaching aids are demonstrated, the multimedia tool plays an important role. The attention of students walks between the teacher and the display. In this ball game watching theory, the demonstrate experience is like the ball game, and the teacher works as an anchor. By following the demonstration proceeding, students build the knowledge by theirselves. In addition, the demonstration must be designed to be interesting in order to make the class proceed fluently. The similarity between the ball game watching and the class will be discussed. Finally we suggest a modern class design which can raise learner motivation and achievement.
\end{abstract}

Keywords: attention, teaching site

\section{INTRODUCTION}

Over the past decade with the rapid development of science and technology, the popularity of computers, mobile phones lead the way of teaching has undergone major changes. The nature of education remains the same, but the teaching methods must keep up with the development of science and technology. Although it is promoted to reform teaching methods, but the classroom did not break through the changes. There is no big difference with the traditional way of teaching. The only iconic expansion may be the increase in multimedia classrooms, teachers can use the projector to teach. The rapid development of the virtual world network, and the close connection of communication software cause the traditional teaching method is difficult to attract students to the classroom, and in the classroom, " Phubber" everywhere is the big problem.

In order to improve the attention in the classroom rate, enhancing the effectiveness of teaching, some schools use the "no mobile classroom" approach. Before the class, students remind each other, the phone shut down or transferred into a quiet mode, and then setting in a special mobile phone Bag, so that students can focus on the lectures. But this is a temporary solution to the negative method, if the teaching content can not attract students, less mobile phone can not guarantee that students can 
concentrate on class, no mobile classroom to provide a quiet external environment, but the teaching effect still depend on the teacher's Teaching ability.

The core value of this teaching theory is "classroom atmosphere". First of all, let us take soccer as an example, why do people want to watch on the pitch? In the huge tens of thousands of people can accommodate the stadium, the audience can not see the distant players without comfortable seats, but people still flocking willing spend a little extra cost to the court to watch the ball. The answer is very obvious, the atmosphere! In the atmosphere of the ball game, the audience was attracted by the game, cheering for a good play, disappointed for a mistake. We will be compared to the classroom with the conduct of the game in this paper. the classroom atmosphere creates a serious impact on teaching quality, and a good atmosphere to drive learning. For example, there is a couple, and the wife is not interested in the ball game. When the husband watching the game at home, no matter how interesting the performance, it is difficult to attract his wife. However, once his wife was pulled to the stadium to watch the game, in the atmosphere, often makes the wife passionate up, and take the initiative to ask some of the rules of the game. From the point of view of learning, this leads to the active learning and it is the most effective learning methods. It is highlighting the importance of the atmosphere affecting the effectiveness of learning.

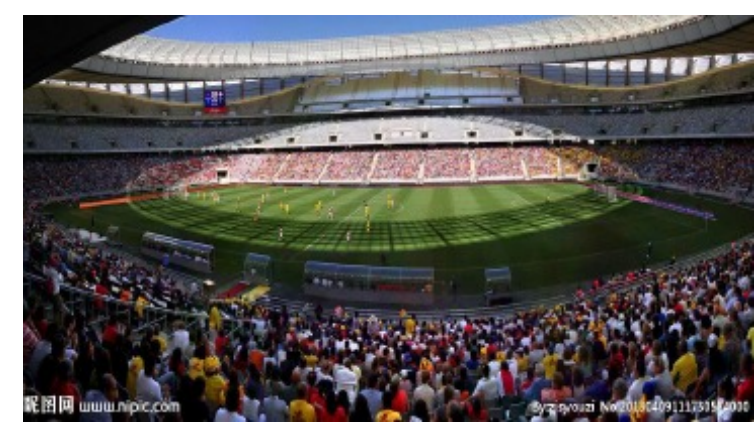

Figure 1. ball game watching

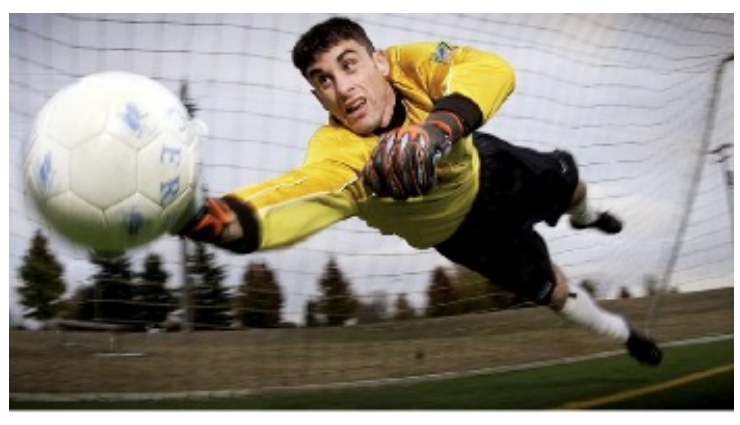

Figure 2. Details by camera

The atmosphere is part of the theory of watching, and the next question is to consider the audience what to see at the scene. Most of the circumstances the audience's attention is to follow the movement of athletes move, but in some important moment, the big screen and telephoto camera must be used to capture the details, and even slow motion playback, this part corresponds to the classroom is the classroom projector and large screen. When the demonstration experiment being done, successfully brought the classroom participation in the atmosphere. The projector and other multimedia electronic equipment, brings the details to the students. It takes both atmosphere and details; this is the core theory of ball watching theory.

\section{OPERATION METHOD}

The current general teaching methods, in the course of science and engineering, is to explain the principles and principles firstly, and then to do the calculation exercises, and finally to have experimental courses. However, this approach is reversed with the "knowledge of the formation sequence". The principle is the result of the hypothesis, that is, principle is the final conclusion. It may miss a lot of speculative process if teaching principles directly, and the innovation is often in the process of speculation. If the teaching design will bring the experiment into the classroom, let the 
students first see the experiment designed according to this theory, first seeing the phenomenon, through the teacher's guidance to get the correct conclusion, the final principle to do the mapping, this learning process is solid and effective. According to expert research, experimental teaching can improve the effectiveness of more than three times.

The practical application of the ball game watch theory has a significant effect on the course of science and engineering. The following example shows a demonstration experiment with "polarized light visualization"

In recent years, the rapid development of liquid crystal display, creating a modern life filled with display, and the basic principle of the LCD display is polarization ${ }^{[1]}$. Humans do not have polarized vision, with the help of polarizers can see the polarization. In the class we use matrix to describe the polarization of light waves, but the polarization behind the mathematics is unable to form a specific impression in the minds of students ${ }^{[2][3]}$, the use of "axis finder" can solve this problem.

The polarizer of the axis finder is along the tangential direction, so that a uniform linearly polarized light will exhibit a symmetrical fan-shaped distribution. The dark area center line is the linearly polarized light direction. Through the axis of the finder can quickly and easily see the direction of polarization.
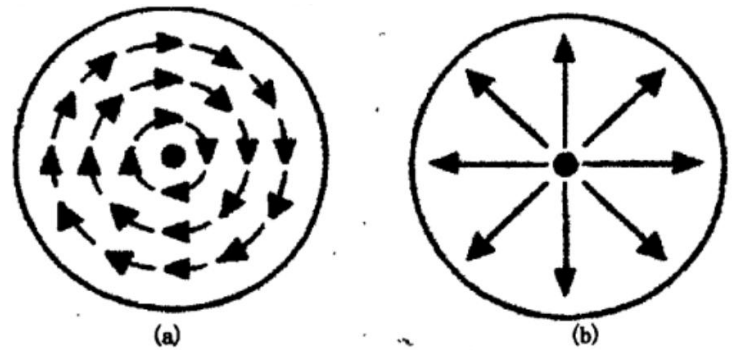

Figure 3. Structure of Axis finder and system set up

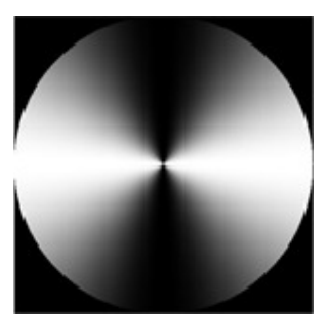

Figure 4. A linear polarized light after axis finder

We designed the experiment to teach the students in the classroom to use the axis finder and find the polarization in the classroom. In the process, the students will find a lot of interesting phenomena that have caused curiosity. Teachers can further quantify this polarization. With the Snell law students can learn more about the cause and size of the polarization, through the observation of the classroom. It help understand of the key concepts obviously.

\section{CONCLUSION}

Ball game watch theory is the result of the experience in the teaching site experience. Through the game match model, the Department of Science and Engineering curriculum design to do a reflection. Students' interest in learning has increased significantly to prove that this is an effective teaching method. For a teacher's curriculum design, with this idea, a piece of glass or a flashlight may be an 
experimental tool in the classroom, But also with the corresponding business companies with the proposed teaching aids, to provide a better teaching platform.

Once high school students just enter the university, the learning methods and teaching methods have been greatly changed. If the knowledge is not interesting enough, it is difficult to switch to new conversion role to become active college students; without the guardianship from high school teachers and parents, some students will be obsessed with the video game and compression of the learning time. It causes a serious impact on the scientific knowledge of the desire and curiosity. The solution may be through some simple real life examples, to cultivate students for the physical, chemical field of interest, and then be able to eager to learn and solve the problem. This requires teachers to rely on a solid theoretical basis and rich practical experience. the abstract knowledge into a specific display teaching, with easy to understand language description. In the ball game watching theory, the classroom will be compared to the stadium, demonstration experiment is the game, the teacher for the broadcaster, conveying the knowledge for the results of this game and the details of the students into the classroom after the attention will be attracted by the experiment, through the teacher's explanation and analysis.

In short, the atmosphere of the classroom is important for the class. In the design of the course, we recommended to the ball game watching theory. It worthies of thinking to do demonstration experimental in the classroom, and giving students the opportunity to think about the principles behind. Then through the projection and other camera to provide clear details, so as the stadium, there are atmosphere with the screen to provide details of the model. So that students interested in the class. A positive environment is created, and provides science and engineering courses a new curriculum design thinking.

\section{REFERENCE}

[1] Hecht, E.. Optics (4th ed.). pp. 352-378 (2001)

[2] Coghill, Anne M.; Garson, Lorrin R. The ACS style guide (3rd ed.). Washington, D.C.: American Chemical Society. (2006)

[3] Polavarapu, Prasad L. "Optical rotation: Recent advances in determining the absolute configuration". Chirality 14 (10): 768-781. 